\title{
PROSODIC EXPRESSION OF EMOTIONAL-AND-PRAGMATIC POTENTIAL OF A SPOKEN ENGLISH PROVERB
}

\author{
LarysaTaranenko \\ National Technical University of Ukraine "Igor Sikorsky Kyiv Polytechnic Institute”, Kyiv, Ukraine \\ litera@i.ua
}

\author{
Steven Schaefer \\ Sorbonne University, Paris, France \\ Steven.Schaefer@paris-sorbonne.fr
}

\begin{abstract}
The paper is a study of the prosodic features involved in the oral actualisation of English proverbs as influenced by structural, emotional and pragmatic factors, which are defined within the framework of a new energetic approach to the research of phonetic phenomena. On the basis of auditory and acoustic analyses of English proverbs, the authors describe the energetic specificity of their prosodic organisation. This description introduces energy-grams formed with the use of a quantitative $K$-criterion of the texts' emotional and pragmatic potentials, as well as their typical intonation patterns. Using the traditional method of linguistic interpretation of the results obtained, the authors substantiate invariant and variant intonation patterns of English proverbs, whose parameters are described both within the text's structural elements and at their junctures. The authors come to the conclusion that an energetic approach to the study of a complex interaction of emotional, pragmatic, semantic and structural factors makes it possible to present a comprehensive description of invariant and variant prosodic patterns for any type of texts on the basis of such fundamental linguistic categories as emotion, pragmatics, structure, and meaning.
\end{abstract}

Keywords: English proverb; pragmatic aim; structural elements; algorithmic model; auditory and acoustic analyses; prosodic means; invariant and variant prosodic patterns; $K$-criterion of the texts' emotional and pragmatic potentials; energy-gram.

\section{Introduction}

In modern linguistics there is a tendency to renovate paradigms using new methodological tools of interdisciplinary studies. This is also true for experimental phonetics, which introduces new theories and research methods aimed at explaining nature and mechanisms of oral speech actualisation. In this regard, the study of the spoken text energetic characteristics based on the principle of preserving the utterance's emotional-and-pragmatic potential (Kalyta, 2015, p. 324) is both interesting and topical.

In view of this, the research objective is to experimentally define the correlation of pragmatic, semantic, structural, and prosodic characteristics of the English proverb, which are jointly realised in oral communication as its definite energetic potential.

\section{Methodological background of the research}

\subsection{The sequence of methodological actions}

The study of the text's energetic characteristics is based on the assumption that an utterance or a text can produce its energetic potential (high, mid, or low), i.e. become valuable for a recipient or at least can catch his/her attention, only when it arouses his/her emotions and feelings. In oral speech the task of triggering human emotions is primarily carried out by prosodic means, which, in their turn, are conditioned by the text's pragmatic, semantic, and structural features. Consequently, it seems expedient to apply in our research methodological stipulations of the speech energetic theory (Kalyta, 2016, p. 72-86) that allows a researcher to view the text prosodic organisation as a result of a complex interplay of emotional, pragmatic, semantic and structural factors.

As a methodological basis for the experimental research, a graphical representation modelling the dynamics of the interaction of emotional and pragmatic potentials, and prosodic and paralinguistic means was utilised (Kalyta, Taranenko 2009). The results of this interaction were graphically represented in the form of energy-grams built with the help of the quantitative $K$-criterion of the level of proverb's emotionaland-pragmatic potential. This criterion, according to the source (Kalyta, Taranenko, 2012, pp. 476-484), was calculated using the formula:

$$
\mathrm{K}=\frac{\mathrm{F}_{0} \times \mathrm{t} \times \mathrm{I}_{0}}{1000 \times \mathrm{I}_{3}}
$$

Legend: $K$-criterion of the level of the utterance emotional-and-pragmatic potential; $\mathrm{F}_{0}$ - fundamental frequency $(\mathrm{Hz})$; 
$\mathrm{t}$ - syllable duration (ms.);

$\mathrm{I}_{0}$ - amplitude of $\mathrm{F}_{0}(\mathrm{~dB})$;

$\mathrm{I}_{3}$ - amplitude of $\mathrm{F}_{3}(\mathrm{~dB})$;

1000 - milliseconds to seconds conversion factor.

Thus, to reach the objective of our research it is necessary to complete the following sequence of methodological steps: to characterise specific functional features of the proverb as a communicative folk genre; to search for an algorithmic scheme of the proverb structure; to evaluate the quantitative $K$-criterion of emotional-and-pragmatic potential of the proverb structural components; to form the graphical model (the energy-gram), representing changes of the proverb's emotional and pragmatic potentials; to explain the correlation of the energetic potential of the proverb structural components and their prosodic organisation.

\subsection{Defining the characteristic features of the proverb as a folk genre}

The proverb, as a folk expression or aphorism with instructive content, conveying in a concise and precise form socio-historical experience and passing it from generation to generation (Mieder \& Mieder, 1981, p. 310; Simpson \& Roud, 2000, p. 286), summarises the observations as to different events or phenomena, specifying their characteristic features and stating a generalised conclusion that can be used to describe similar events or phenomena (Caro, 1986, p. 184). Due to this, proverbs perform their associative and educational function in society.

Applying this to one of the greatest paradoxes of the proverb, we shall note here that linguists usually view it as the epitome of simplicity and common sense. However, according to K. Lau's remarks, the proverb represents a much more complex composition to be unambiguously defined, since, although most people use them almost every day, few can precisely say what makes them proverbs. Therefore, having been under study for centuries, the proverb has many different definitions (Lau et al., 2004, p. 2).

The overwhelming majority of researchers are unanimous in recognising the fact that in the foundation of the didactic nature of the proverb, aimed at encouraging people to observe and follow certain moral norms, underlies folk wisdom, verified by the experience of previous generations (Carnes, 1994, p. 475; Obelkevich, 1994, p. 213).

In accordance with academic interpretations, the proverb is an aphoristically compressed, figurative, grammatically and logically complete expression of instructive content. At the same time, it is defined (Oring 1986, p. 184) as a statement that is "passed on in fixed form by oral transmission and assumed to convey some ethical or philosophical truth or some other wise observations about life, the world around us, or human nature". Proverbs are also described as "short, crisply structured sayings widely known in a community, which convey traditional observations on moral judgments, mockery, warnings, etc." (Simpson \& Roud, 2000, p. 286).

Seeing a direct correlation between proverbs and typical social situations, some researchers view them as a conventional means of speech activity or a "shorthand" method of communication (Oring, 1986, p. 186), i.e. as a ready-made powerful statement, a proverb conveys a culturally agreed-upon idea which can be used to make a succinct and effective point. According to other scholars, proverbs represent a "social solution to situations" (Albig, 1931, p. 529), serve as socialisation maxims, are the means of expressing judgments and a tool for solving some communication problems in social stereotype situations (Taylor, 1994). From these and other definitions it is clear that the proverb's main function is a didactic one that serves to fulfil the associative-and-educational purpose in society.

Using what was stated above as the basis, we can formulate a generalised definition, according to which the proverb is a lapidary folk genre of a didactic value, which by means of summarising human sociohistorical experience, transmits to future generations leading moral, ethical, philosophical and everyday ideas as to comfortable existence in the surrounding reality.

\subsection{Identifying the algorithmic pattern of English proverb's structure}

The results of our previous study of the algorithmic structure of small English folk texts (Taranenko, 2017) confirm the expediency of further search for structural and content-based archetypes, which eventually directly or indirectly participate in the formation of larger literary texts.

According to Dandes (as cited in Bronner, 2007, p. 29), the proverb in terms of their propositional structure are the traditional statements that contain at least one descriptive element that includes the topic, represented by the referent, and a commentary that describes the form, function or action of the topic. Thus, the proverb is composed of at least two words (Honeck, 1997, pp. 23, 92) (e.g., Time flies (Bukovskaya et al., 1990, p. 175), Money talks (p. 135)). The proverbs that contain only one descriptive element are unoppositional, while proverbs having two or more descriptive elements may be either oppositional or non- 
oppositional (Like master, like man (Bukovskaya et al., p. 129), Little thieves are hanged but great ones escape (p. 202)). The opposition creates a commentary that can be decoded by the addressee.

To understand the practically unlimited multitude of possible combinations of "referent" and "commentary" as dual elements of the proverb's structure as well as alternative variants of their interaction, we analysed 800 English proverbs, chosen from various paremiographical collections (Bukovskaya et al., 1990; WDP, 1995).

Thus, in the proverbs An Englishman's home is his castle (Dubenko, 2004, p. 38), Money is the root of all evil (Bukovskaya et al., p. 134), Every medal has its reverse side (Dubenko, 2004, p. 370), Money is the sinews of war (p. 83), Handsome apples are sometimes sour (p. 144) there is an interaction between the thing (the referent) and its feature (commentary), whose relation can be marked as the "thing - feature" relation.

Then the dual interaction of the structural components of the other group of proverbs can be indicated as "phenomenon - evaluation": A great fortune is a great slavery (Dubenko, 2004, p. 24), Meekness is not weakness (p. 74), Poverty is no sin (p. 27), Common sense is genius dressed in its working clothes (p. 72), Welcome is the best dish on the table (p. 79).

The following proverbs can serve as the examples of the interaction between the referent and the commentary according to the formula "action - conditions of its achievement": Try before you trust (Dubenko, 2004, p. 64); An apple a day keeps the doctor away (WDP, 1995, p. 13); Ask no questions and you will be told no lies (Bukovskaya et al., 1990, p. 150); Virtue would not go far if a little vanity walked not with it (Dubenko, 2004, p. 91); The woman who obeys her husband rules him (p. 128).

A group of proverbs having the formula "action - its consequences" comprises such examples: Who spits against the wind spits in his own face (Dubenko, 2004, p. 161); If the blind lead the blind both shall fall into the ditch (Bukovskaya et al., 1990, p. 34); He that hesitates is lost (p. 181); Constant dropping wears away a stone (p. 78); Who keeps company with the wolf will learn to howl (p. 153); As a man sows, so shall he reap (Dubenko, 2004, p. 266); Injure others, injure yourself (Bukovskaya et al., 1990, p. 88); Who seeks a faultless friend stays friendless (Dubenko, 2004, p. 105); Tell a woman and you tell the world (p. 126); Who spends before he thinks, will beg before he dies (p. 117).

The formula "behaviour - opposition" can be described by the following proverbs: He is a fool who cannot be angry but a wise man who will not (Dubenko, 2004, p. 73); He that spills the rum loses that only; he that drinks it often loses that and himself (p. 238).

The following group of proverbs can be characterised by the formula "intention - conditions of its achievement": One cannot be too careful (Bukovskaya et al., 1990, p. 45); When all are poor, it doesn't take much to make a rich man (Dubenko, 2004, p. 30); Where there is a will, there's a way (p. 31).

The following proverbs serve as illustrative examples of the interaction between the referent and the commentary according to the formula "state - conditions of its achievement": To be content, look backward on those who possess less than yourself, not forward on those, who possess more (Dubenko, 2004, p. 29); A genius is born not made (p. 72); Nothing can bring you peace but yourself (p. 74); Women are strong when they arm themselves with their weaknesses (p. 129).

The next group of proverbs can be described by the formula "state - incompatibility": A hungry belly has no ears (Dubenko, 2004, p. 24); It is easier for a camel to go through the eye of a needle than it is for a rich man to enter the kingdom of heaven.) (p. 25); Wealth and content are not bedfellows (p. 30).

We shall finish with the examples of proverbs, grouped by the formula "misdeed - consequence": Set a beggar on horseback and he will ride to the Devil (Dubenko, 2004, p. 29); Give a man enough rope and he will hang himself (Bukovskaya et al., 1990, p. 154).

We are to remark here that the multitude of definite interactions between the referent and the commentary of the proverb is much broader and may cover such their alternative correlations as: "phenomenon - characteristics", "phenomenon - evaluation", "misdeed - consequences", "intention condition of achievement", "intention - reality", "intention - incompatibility", "intention - result", "intention - payment"; "dream - reality", action - conditions of its achievement", "action - consequences", "action - warning", "action - incompatibility", "action - prediction", "event - significance", behaviour requirements", "state - evaluation", "state - conditions of achievement", "state - consequences", "state incompatibility", "state - temptation", "state - restrictions", "condition - advice", "significance evaluation", "significance - condition of its achievement and so on.

Given the limited possibilities of graphic representation of the system of alternative structural components of the proverb, we have built only a fragment of it (see Fig. 1), presenting the interaction of referents and commentaries of the proverb in the recipient's mind. 


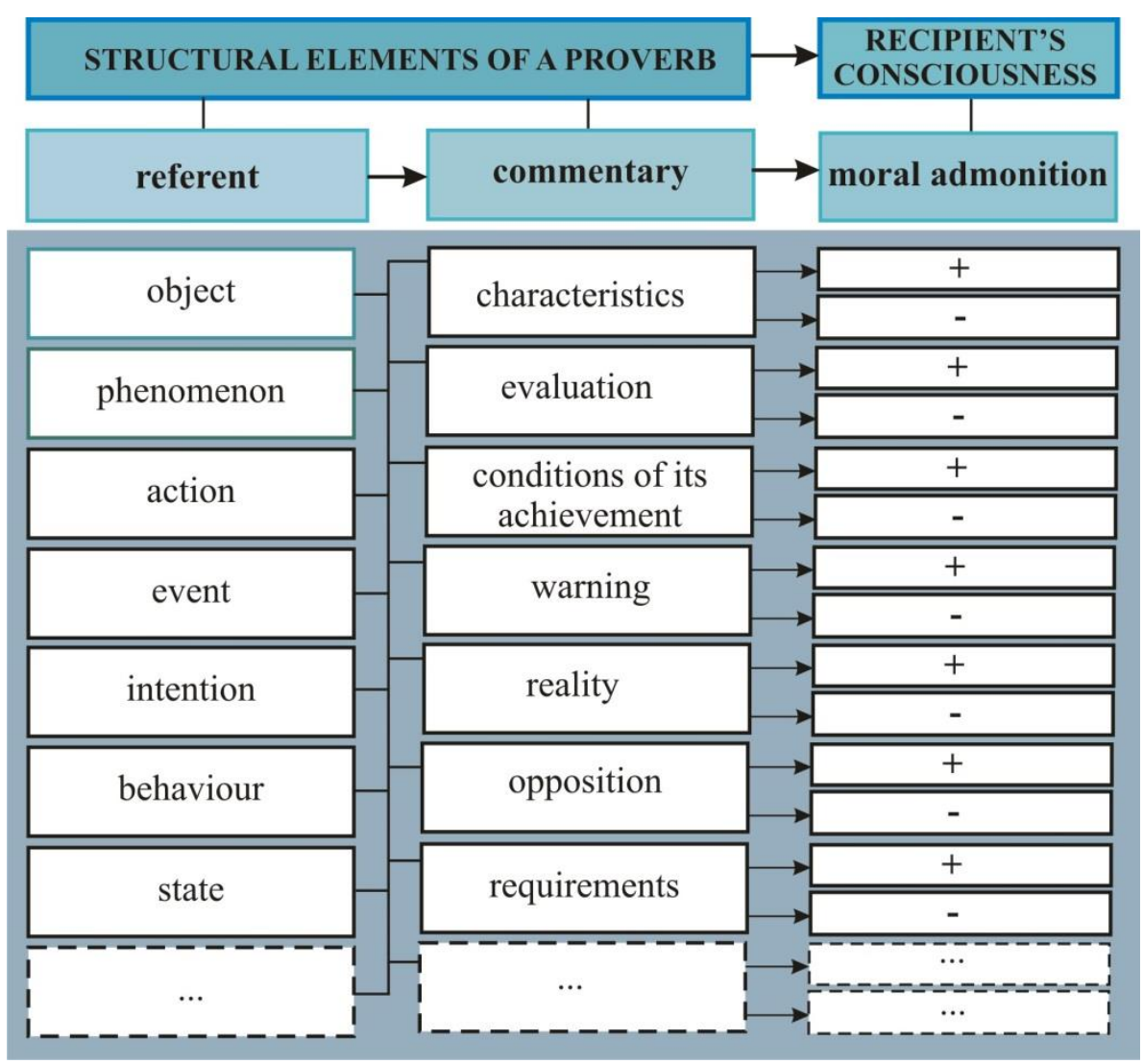

Fig. 1. Fragment of the analysis of "referent" - "commentary" interaction in the recipient's consciousness

The model demonstrates (see the links between the columns) that any "referent" can potentially interact with a number of "commentaries", thus creating the structures of definite proverbs, e.g.: action - conditions of its achievement, action - evaluation, action - opposition, action - reality, action - requirement, action warning, etc.

We should also pay attention to the fact that as a result of the perception of the proverb's "referent" and "commentary", the recipient's consciousness decodes its guidelines whose polarity is preconditioned by the interaction of their meanings. Thus, the centuries-old wisdom of the proverb fixes in the recipient's consciousness a positive or negative attitude to the most typical events occurring in the cultural and everyday life of the individual.

The stated above as well as the results of the content analysis presented in Fig. 1 served as the basis for constructing an algorithmic model of the proverb's structural components interaction in the recipient's mind (Fig. 2).
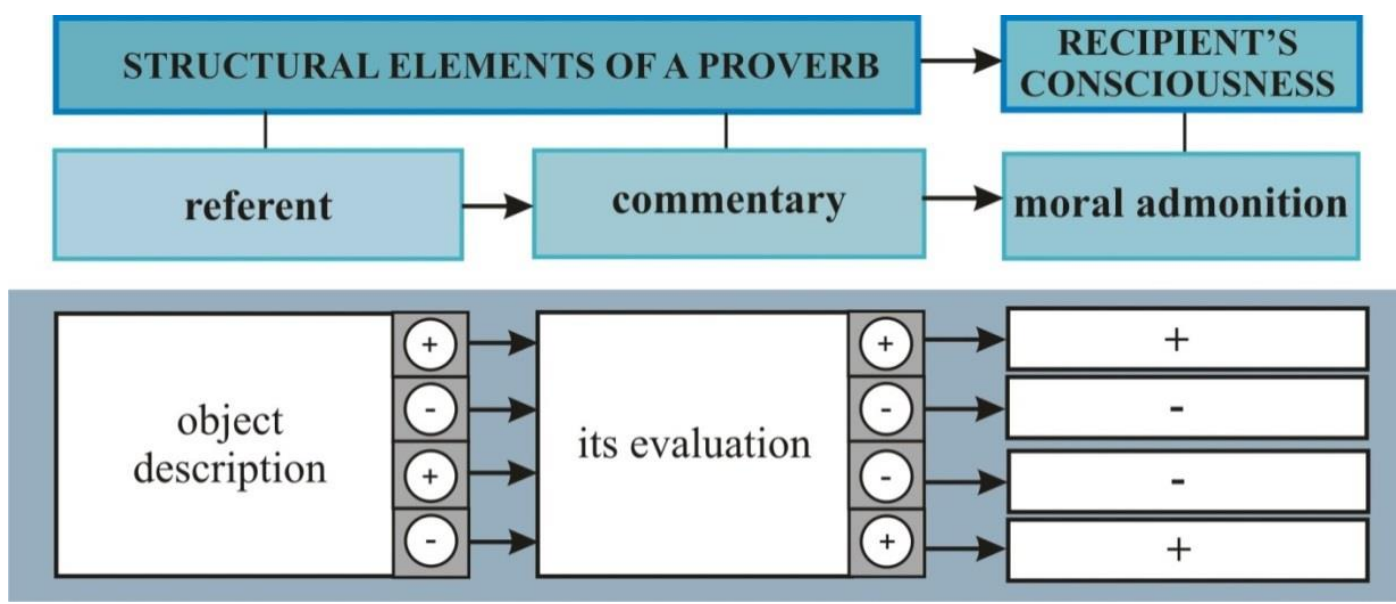

Fig. 2. Algorithmic model of the "referent" - "commentary" interaction that leads to decoding positive or negative moral admonition of the proverb 
In the process of this model formation, due to the high level of its abstraction, we unified the alternatives of "the referents" into their more general groups: the thing, phenomenon, intention, action, behaviour, state, as well as defined thus formed class of referents from the recipient's point of view as the "object description". Similarly, by summing up the functional and semantic value of "the commentary", we applied for it the term "evaluation". Besides, positively evaluated objects were marked by $\bigodot$. Accordingly, negatively evaluated objects were marked by the sign $\odot$.

As a result, we obtained the algorithmic model (see Fig. 2) describing the structure of all the English proverbs under study: "referent (the object description) $\rightarrow$ commentary (the object evaluation) $\rightarrow$ moral admonition".

It becomes clear that the proverb's high degree of lapidarity, which is manifested in its limited compositional structure, causes the additional loading on the recipient's cognitive-and-creative mechanism in the process of its decoding. At the same time, the limitation of its structural components is compensated, as a rule, by a number of the alternatives semantic elements (action, quality, intention, desire, dream, phenomenon, state, significance, principle, error, flaw, etc.), which due to a definite prosodic pattern of their oral actualisation can be decoded by the addressee in the form of positive (appraisal or encouragement) or negative (disapproval of certain deeds) moral guidelines.

\section{Results of the experimental analysis of a proverb energetic potential}

The auditory analysis was performed in compliance with a theoretically justified and practically verified postulation concerning the rationality of performing a description of prosodic patterns representing dynamic changes of the text emotional and pragmatic potentials within its algorithmic structural elements (Taranenko, 2017).

Thus the experimental study of actualising English proverbs by prosodic means was carried out in accordance with the algorithmic model of the structure of their text (see Fig. 2), that consists of such dual elements: "referent - commentary". Considering their functional loading, in the course of our study we also applied to these components their synonymous terms, signifying the referent of the proverb as "the object of understanding", and its commentary - as "the evaluation of the object".

Since both structural elements described in the proverb can acquire either positive or negative evaluation depending on the particular communicative situation, we analysed English proverbs as they occurred in the context of literary works. Thus formed, the corpus of experimental texts under study amounted to 142 English proverbs, selected from different texts of fiction, whose total sound duration is of 2.5 hours.

We also paid attention to the fact that the proverb, being an effective communicative and educational tool, is characterised by the minimum number of lexical, grammatical, and stylistic means as well as by a lapidary presentation of ethical, philosophical or generalising ideas about everyday reality. This gives us every reason to emphasise the importance of prosodic means in conveying changes in emotional and pragmatic potentials within the structural components of proverbs.

The estimation of energetic characteristics of the proverbs' structural elements has shown that, being spoken out of context, they have a low level of pragmatic potential. It does not change throughout the actualisation of the proverb, whose functional purpose in this case is just to acquaint the listener with a certain general idea. Regarding the emotional potential of such a proverb, which is also of a low level, it always has an ascending movement within the structural element the "referent" and a descending one within the "commentary".

As to the dynamics and polarity of the emotional potential of proverbs used in context, they vary depending on the information that precedes and /or follows the proverb. At the same time, the pragmatic potential of the proverbs used in context, is, as a rule, somewhat higher than the emotional one and tends to gradually grow, always reaching its highest level (whether it is medium or high) on the rhetorical element of the evaluation of the object described in the proverb (the commentary).

We shall illustrate the stated above with the energy-grams of the proverbs spoken in isolation in the first example (while teaching English to familiarise the audience with the meaning of the proverb), and in the context of a literary work - in the second one:

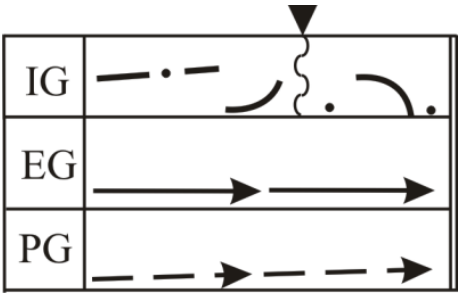

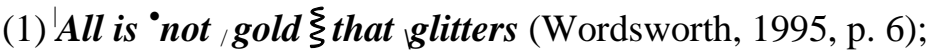


(2) "I am sorry to grieve you", pursued the widow; "but you are so young, and so little acquainted with men, I wished to put you on your guard. It

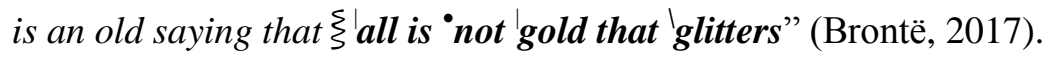

The comparison of the proverb's emotional and pragmatic potentials depicted in energy-grams and their intonational organisation shows that in the first example (1) the proverb is emotionally neutral and it is emotionally coloured in the second one (2). Thus, the example (1) has a low level of

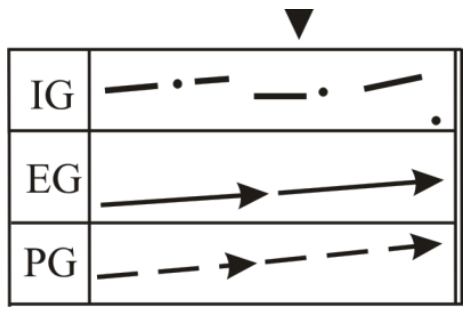
emotional potential which remains practically unchanged during the proverb's actualisation and we observe a slight increase in its pragmatic potential which at the prosodic level is realised by means of a checked scale combined with a low rising terminal tone in the first intonation group and a low falling tone - in the second one.

In example (2) there is a simultaneous growth of the emotional and pragmatic potentials of the proverb to the middle level, whose peak is realised on the terminal part of the intonation group ('glitters), which structurally is "a commentary" and thus conveys the rhetorical information of the whole proverb. In contrast to the example (1), whose intonational means only accompany lexical and grammatical ones, expressing its generalising meaning, in the example (2) prosodic means act as a leading tool while actualising the emotional-and-pragmatic potential of the proverb, aimed at warning the listener against unreasonable deeds. The proverb acquires such a functional loading due to: (1) its actualisation within one intonation group, having a complex type of rhythm; (2) the emphasis of the word Igold, which is a part of the structural element "referent", with a negative pitch interval, and the word 'glitters, representing the structural element "commentary" - with a positive pitch interval and emphatic contour of the high falling terminal tone (i.e. having a direct ascending movement on the accented element 'glit- with the following level movement on the unstressed tail -ters).

The research has shown that, irrespective of the specific functional aim of the proverb (advice, approval, disapproval, inducement, encouragement, warning, etc.), all English proverbs are characterised by a maximum level of their pragmatic potential within the structural element "commentary", achieved as a result of a complex interaction of a number of the following intonation parameters.

Thus, within the "commentary" we registered in one intonation group the combination of several variants of high falling kinetic tones, actualised in different register keys: a narrow one having a downward movement with an incomplete descend, which serves to emphasise an additional semantic centre of the "commentary", and a falling tone of a wide range passing through all the register keys. For example, in the proverb 'Birds of a feather $\xi$ flock to'gether. \| (Carroll, 1994), both words of the "commentary" (flock to'gether) are made prominent. The word 'flock is intensified by a wide positive pitch interval at the junction of the proverb's two structural elements as well as due to having a high falling tone of a narrow range, as we can see it from the tonogramme:

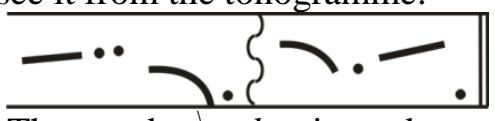

The word to gether is made prominent (a) by the widened range of a high falling tone, which starts at a low level of a high key and ends in the upper register of the lower key, i.e. it passes through almost all key registers, and (b) by its structures (the full fall into the lower level of the lower key register on the tail with a preceding direct upward movement within the high key on the stressed syllable).

Another way of emphasising the pragmatic value of the structural element (the "commentary") is the actualisation within its intonational structure of a special rise (1) and pitch intervals (2), as shown in the examples:

(1) “A ' good,conscience $\xi \mid$ makes a $\uparrow$ sound sleeper," $\|$ he observed (Christie, 2005);

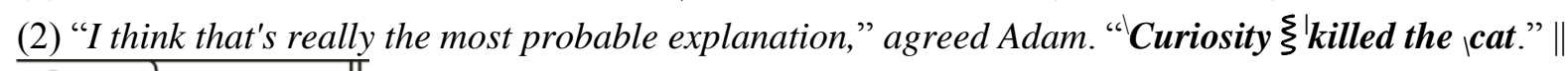

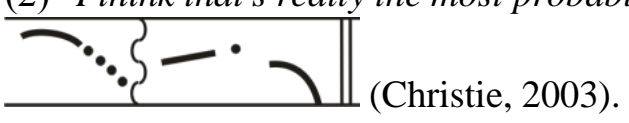

The given examples demonstrate the intensification of the rhetorical element of the "commentary" by the preceding pitch interval, which is achieved either by the presence of a special rise, or by the ascending movement of the head.

According to the data received from the auditors, this very interplay of prosodic means of the element "commentary" that results in its wave-like melodic contour (due to the presence of two kinetic tones, the difference in their structure, their key differences, pitch intervals at the juncture of all intonation group sections, various pitch levels of its beginning and end, the use of a broken descending stepping head), serves to highlight the additional semantic centre of the "commentary"; this causes the increase in emotional-and- 
pragmatic potential of the whole proverb to the middle or high level as well as communicates its subliminal effect, directing the listener to correctly decode the proverb's admonition and making him/her perceive the proverb not merely as a generalising statement, but rather as a guideline as to existence in certain conditions within a society.

The structural element the "referent" is actualised, as a rule, at a low level of emotional-and-pragmatic potential, since it has the form of the statement and consequently is organised by the corresponding prosodic parameters: moderate tempo and loudness, the absence of abrupt pitch fluctuations, the use of a low falling or level terminal tone in its final rhythmic group, for instance:

"The $\rightarrow$ past $\xi$ is the father of the present", || said Poirot sententiously (Christie, 2006).

“Dead $\downarrow$ men $\xi$ tell $\uparrow$ no $\backslash$ tales, $\| ”$ he said evenly (Christie, 2013).

Proverbs that consist of two or more syntagms which correspond, respectively, to different structural elements, are characterised, unlike mono-syntagmatic proverbs, by the presence of lexico-semantic and prosodic contrasts, for example:

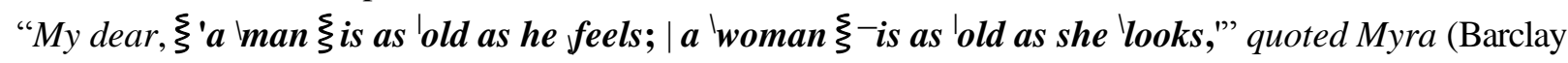
2015).

In this proverb, whose structural elements are detached by the mid-length pause, each word acquires a prosodic contrast, and, consequently, the rhythmic groups of the proverb are also opposed to each other. Thus, the highest degree of prominence is given to the words man and woman, uttered with high falling tones of a wide range that have different configurations: a convex one on the word man and ascending-descending - on the word woman. The lexical units feels and looks are contrasted due to having a different pitch level of the falling tones: the low falling tone of the narrow range marks the word feels, while the word looks is pronounced with a high falling tone of a wide range that begins in the low register of the upper key and passes through all the tonal keys. The same word 'old, which in both structural elements is the head of the checked scale, is also contrasted by its pronunciation on different pitch levels: in the "referent", that has the form of statement, the word ' old is uttered at a lowered pitch level, while in the "commentary" that actualises the functional objective of this proverb as an advising and reassuring encouragement, this word sounds at a heightened pitch level. As we can see, the prosodic accompaniment of semantic contrasts leads to the increase in both emotional and pragmatic potentials of the proverb towards the "commentary", thus realising its definite social purpose, in this case living the advice as to the adequate behaviour in society.

In the course of our study we also paid attention to the peculiarities of prosodic demarcation of the transition (or juncture) from the literary text fragment to the proverb. It has been confirmed that a proverb inserted into the structure of another sentence is usually preceded by a long pause in combination with the level or rising terminal tone actualised with a low rate of changing its movement direction, which together serve to make the listener ready to perceive the meaning of the proverb, for example:

"Personally I should loathe anyone reading aloud to me." "WWell, well, | tastes 'differ," I said (Christie, 2004).

The analysis also showed that the length of the pause preceding the proverb depends on the pragmatic orientation and functional aim of its textual fragment. In other words, if the speaker uses a proverb to summarise the previously stated information, he/she takes a long pause that prepares the listener to perceive the proverb as a certain inference and allows him/her to have some time to comprehend its pragmatic guidance, that is, according to the findings by Kalyta (2014), performs a subliminal influence on the listener by triggering cognitive processes of his/her thinking mechanisms (p. 52), for example:

From now on, it is our task to suspect each and every one amongst us. $\|^{\mid}$Fore,warned $\xi$ is $\mid$ forevarmed (Christie, 2011).

In this fragment, according to the informants, the subliminal effect of the proverb is provided by the means of all the subsystems of intonation (tonal, dynamic, and temporal). Thus, a long pause that precedes the proverb in combination with the wave-like melodic contour of the whole fragment, the highlighting of each syllable of notional words with the stress and terminal tone, slowing down of tempo, actualisation of the regular rhythm, reinforces the pragmatic component of the emotional-and-pragmatic potential of the proverb, allowing the listener to unambiguously interpret it as a warning of a potential danger.

A similar function is realised by a long pause that precedes the proverb in the fragment "I think that's really the most probable explanation," agreed Adam. || “Curiosity కlkilled the cat." || (Christie, 2003). As in the example above, the unmistakable decoding the negatively-marked instruction of the given proverb, i.e. disapproval and condemnation of the character's deeds, is enhanced by the interaction of prosodic means. Thus, the proverb is singled out against the background of the emotionally-neutral previous fragment with a high pitch level of its beginning, a widened voice range, the increase in loudness and deceleration of tempo 
within the "commentary". In this case the proverb serves to convey in a precise manner the negative evaluation of the information contained in the fragment preceding it. Because of this, both structural elements of the proverb acquire the prominence: (1) the "referent", represented by the word 'curiosity, is emphasised by a high falling narrow tone of incomplete fall; (2) within the intonation group of "commentary" ('killed the ${ }_{\mid c a t}$ ) its terminal part ${ }_{1}$ cat is intensified with the negative pitch interval. Due to the equal prosodic prominence of both structural elements, the proverb acquires a middle level of its emotional potential, which remains unchanged throughout the whole proverb. Regarding its pragmatic potential, similarly to all the analysed proverbs, it gradually grows in the direction of the structural element "commentary".

The analysis carried out shows that the positive or negative evaluation of structural elements of the proverb is achieved through the interaction of prosodic parameters within the intonation groups of structural elements and at their junctures, which, in combination with the lexical and grammatical means, can ensure a correct decoding of a proverb's positive (appraisal) or negative (condemnation) moral guidelines in the recipient's mind.

At the next step of our experimental study we calculated the $K$-criterion of each stressed syllable of the analysed proverbs and came up with their average measures which allowed us to build a typical energy-gram of an English proverb, that represents changes of the proverb's emotional and pragmatic potentials within its structural elements ("the referent" and "the commentary"), as shown in Fig. 3.

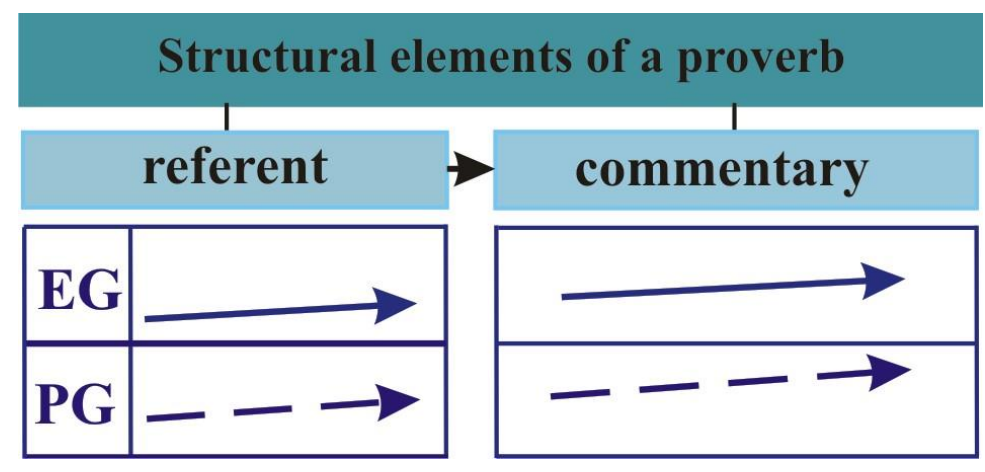

\section{Fig. 3. A typical energy-gram of the English proverb oral actualisation}

The evaluation of the energetic characteristics of the proverb showed that "the referent" has a low level of emotional and pragmatic potentials $(K=18,6)$, since it is pronounced within a mid-level pitch range, with moderate tempo and loudness. It lacks pitch fluctuations and its final rhythmic group has a low falling, rising or level tone: “Dead men $\mid$ tell $\uparrow$ no \tales, ||"; It is an old saying that §lall is 'not 'gold that 'glitters".

Irrespective of the proverb functionality (advice, encouragement, warning, ridiculing, etc.), all English proverbs have the highest level of their pragmatic potential in the "commentary" $(K=42,4)$. It is achieved due to a widened pitch range, a special rise and pitch intervals within its intonation structure, tempo acceleration and loudness increase, combination of several high falling tones within one intonation group ('Birds of a feather |'flock to'gether \|; “My dear, §'a 'man $\xi$ is as 'old as he feels; | a 'woman $\xi$-is as 'old as she 'looks'||").

The energy-gram (Fig. 3) shows a simultaneous growth of the proverb emotional and pragmatic potentials throughout its sounding. At the same time, the emotional potential gradually increases to a high zone of a low level within the structural element "referent" and continues to grow to the middle level in the "commentary".

The pragmatic potential of the proverb is somewhat higher than the emotional potential and also tends to gradually grow, reaching its highest level (middle or high) in the structural element the "commentary". Consequently, the "commentary", which communicates the rhetorical information of the entire proverb, is marked, as compared with the "referent", by a higher level of emotional-and-pragmatic potential.

\section{Conclusions}

The study showed that the dynamics and polarity of the proverb's emotional potential varies depending on the information that precedes or follows the proverb. However, the proverb's pragmatic potential is higher than the emotional potential and tends to gradually increase, reaching its mid or high level on the key-word of the "commentary". 
The analysis carried out proves that due to the lapidary nature of the text and the increased cognitive loading of the proverb's actualisation in oral communication, the speaker uses such prosodic means, which interacting with a limited variety of the proverb lexical and grammatical means - can excite in the listener's psyche relevant feelings and emotions, whose absence reduces the instructive effect of the proverb and lowers the possibility of the fixation of the proverb's moral admonition in the recipient's mind, which is aimed at realising its associative and educational functional aim.

\section{References:}

Albig, W. (1931). Proverbs and Social Control. Sociologic and Social Research, 15, 527-535.

Apperson, G. L., (Ed.). (1995). The Wordsworth Dictionary of Proverbs. L.: Wordsworth Reference.

Bronner, S. J. (Ed.). (2007). Introduction: The Analytics of Alan Dundes. In Meaning of Folklore: The Analytical Essays of Alan Dundes (pp.1-35). Utah State University Press, University Press of Colorado. https://doi.org/10.2307/j.ctt4cgrzn

Barclay, F. L. (2015). The Rosary (audiobook). Retrieved December 15, 2017, from https://www.youtube.com/watch?v=A4IWTF0fa_o.

Brontë, Ch. (2017). Jane Eyre [Audiobook; read by Juliet Stevenson]. Retrieved December 16, 2017, from https://www.youtube.com/watch?v=MEW1pJKIKPM.

Bukovskaya, M., Vyaltseva, S., \& Dubyanskaya, Z. (Eds.) (1990). A Dictionary of English Proverbs in Modern Use. Moscow: Russky Yazyk Publishing House.

Carnes, P. (1994). The Fable and the Proverb. Intertexts and Reception. In W. Mieder (Ed.), Wise words : Essays on the proverb (pp. 467-493). N.Y.: Garland.

Caro, F. A. de (1986). Riddles and Proverbs. In E. Oring (Ed.), Folk Groups and Folklore Genres : An introduction (pp. 175-197). Logan: Utah State University Press.

Carroll, L. (1994). Alice's Adventures in Wonderland (audiobook). L.: Penguin. Audio Cassettes 1 (94 mins), 2 (68 mins).

Christie, A. (2003). Cat Among the Pigeons (audiobook; read by Hugh Frazer). HarperCollins Publishers Ltd; Unabridged edition. 6 CDs.

Christie, A. (2004). Curtain [Audiobook; read by Hugh Frazer]. HarperCollins Publishers Ltd; Unabridged edition. 5 CDs.

Christie, A. (2005). Affair at Styles [Audiobook]. BBC Books; Unabridged edition. 2 CDs, Running Time : 2 hrs 30 mins.

Christie, A. (2006). Halloween Party [Audiobook; a BBC radio 4 full-cast dramatisation]. BBC Books; Unabridged edition. 2 CDs.

Christie, A. (2011). And Then There Were None [Audiobook]. BBC Books; Unabridged edition. 2 CDs, Running Time : $1 \mathrm{hr} 30 \mathrm{mins}$.

Christie, A. (2013). Secret Adversary [Audiobook; read by Judi Pennington]. Cherry Hill Publishing.

Dubenko, O. (2004). English-American proverbs and sayings. Vinnytsia: Nova Knyha Publishing House.

Honeck, R. P. (1997). A Proverb in Mind: The Cognitive Science of Proverbial Wit and Wisdom. Mahwah, NJ: Lawrence Erlbaum Associates.

Kalyta, A. (2015). Phonetic studies from the perspective of an energetics approach. In A. Bondaruk \& A. Prazmowska (Eds.), Within language, beyond theories (Volume I): studies in theoretical linguistics (pp. 322-336). Cambridge: Cambridge Scholars Publishing.

Kalyta, A. (2016). Speech Energetics. Kyiv: Kafedra Publishing House.

Kalyta, A., \& Taranenko, L. (2012). Perceptivna j instrumental'na ocinki emocijno-pragmatichnogo potencialu vislovlen' [Auditory and instrumental evaluation of the utterance emotional-and-pragmatic potential]. Naukovij visnik Volins'kogo nacional'nogo universitetu imeni Lesi Ukraunki. Serija: Filologichni nauki: Movoznavstvo, 24 (249), 186-191.

Kalyta, A. (2014). Problem of Studying Speech Pauses' Energetic Potential. In Book of Abstracts of the II International Linguistics Conference Linguistics (Poland, Lublin, 6-7 November 2014), Linguistics Beyond and Within: Challenging Ideas and Innovative Applications (pp. 51-53). Poland, Lublin: John Paul II Catholic University of Lublin.

Lau, K. J. (2004). What Goes Around Comes Around: The Circulation of Proverbs in Contemporary Life. In K. J. Lau, P. Tokofsky \& S. D. Winick (Eds.), What Goes Around Comes Around: The Circulation of Proverbs in Contemporary Life : Essays in honor of Wolfgan Mieder (pp. 1-19). Logan: Utah State University Press.

Mieder, B. \& Mieder, W. (1981). Tradition and innovation: Proverbs in advertising. In W. Mieder \& A. Dundes (Eds.), The Wisdom of many : Essays on the proverb (pp. 309-322). N.Y.: Garland Publishing, Inc.

Obelkevich, J. (1994). Proverbs and Social History. In W. Mieder (Ed.), Wise Words: Essays on the Proverb (pp. 211-252). N.Y.: Garland.

Oring, E. (1986). Riddles and Proverbs. In E. Oring (Ed.), Folk Groups and Folklore Genres: An Introduction (pp. 175-198). Logan: Utah State University Press.

Simpson, J. \& Roud, S. (2000). A Dictionary of English Folklore. Oxford: Oxford University Press.

Taranenko, L. (2017). Correlation of the English Fairy Tale's Plot Structure and its Prosodic Organisation. Advanced Education, 7 , 114-122. https://doi.org/10.20535/2410-8286.105385

Taylor, A. The Wisdom of Many and the Wit of One. In W. Mieder \& A. Dundes (Eds.), The Wisdom of Many: Essays on the Proverb (pp. 3-9). Wisconsin: The University of Wisconsin Press. 